\title{
CONSTRUÇÃO E VALIDAÇÃO DA ESCALA DE RACISMO REVITIMIZADOR
}

Marcus Eugênio Oliveira Lima

Universidade Federal da Paraíba

Isabelle Haaiara Andrade Barbosa

Universidade Federal de Sergipe

Erick Matheus Santos Araujo

Universidade Federal de Sergipe

Juliana Nascimento de Almeida

Universidade Federal de Sergipe
Recebido em: 11/09/2019

$1^{\text {a }}$ revisão em: 18/02/2020

Aceito em: 18/05/2020

\section{RESUMO}

O racismo apresenta duas características centrais: persistência e adaptação. Considerando as mudanças sociais e políticas do Brasil na atualidade, hipotetizase que ele atue mediante atribuição de culpa às minorias pela existência do próprio racismo, numa lógica de revitimização. Neste artigo procedemos a construção e validação de uma Escala de Racismo Revitimizador (ERR). Foram realizados dois estudos. O primeiro ( $\mathrm{n}=121,50,4 \%$ do sexo feminino, idade média $=25,3, D P=10,2$ ) procedeu a uma análise de conteúdo de posts na internet para a construção e confirmação da ERR. O segundo ( $n=104,54,8 \%$ de sexo masculino, idade média $=22,9, \mathrm{DP}=7,3$ ) procedeu a validação convergente com o racismo moderno e discriminativa com o autoritarismo, bem como Análise Fatorial Confirmatória e correlações com a motivação interna/externa para responder sem preconceito. Os resultados demonstram que a ERR é menos obstrutiva que a escala de racismo moderno e apresenta validade convergente e discriminativa.

Palavras-chave: estudo de validação; escala de racismo; vitimização secundária; conservadorismo. 


\section{CONSTRUCTION AND VALIDATION OF REVITIMIZER RACISM SCALE}

\section{ABSTRACT}

Racism presents two central features: persistence and adaptation. Considering social and political changes of Brazil nowadays, it is hypothesized that acts by attributing blame to minorities for the existence of racism itself, in a logic of revictimization. This article proceeds the construction and validation of a Revictimize Racism Scale (RRS). Two studies were carried out. The first ( $n=121$, $50,4 \%$ female, mean age $=25,3, S D=10,2$ ) dealt with the RRS construction, based on racist content the analysis of Internet. The second ( $n=104,54.8 \%$ male, mean age $=22.9, \mathrm{SD}=7.2$ ) proceeds to convergent validation with modern racism and discriminative with authoritarianism, such as Factorial Confirmatory Analysis and correlations with internal/external motivation to respond without prejudice. The general results allow us to conclude that the RRS is less obstructive than that of modern racism and has satisfactory convergent and discriminant validity.

Keywords: validation study; racism scale; secondary victimization; conservatism.

\section{CONSTRUCCIÓN Y VALIDACIÓN DE LA ESCALA DE RACISMO REVITIMIZADOR}

\section{RESUMEN}

Racismo presenta dos rasgos centrales: persistencia y adaptación. Considerando los reciente cambios sociales y políticos de Brasil, hipotetizamos que el racismo opera por la atribución de culpa a las minorías, afirmando que este actúa atribuyendo la culpa a las minorías por la existencia del racismo en sí, en una lógica de revictimización. Proponemos un instrumento para analizar el Racismo Revitimizador. Se realizaron dos estudios. El primero ( $n=121,50,4 \%$ mujeres, edad media $=25,3, D P=10,2$ ) trató de la construcción del instrumento, partiendo del análisis de contenidos racistas en internet. El segundo ( $n=104,54,8 \%$ hombres, edad media $=22,9, D P=7,3$ ) procede a la validación convergente con racismo moderno y discriminatorio con autoritarismo, a través de Análisis Factorial Confirmatorio y correlaciones con la motivación interna/externa para responder sin prejuicios. Los resultados indican que ERR es menos obstructiva que la de racismo moderno y presenta validez convergente y discriminativa.

Palabras clave: estudio de validación; escala de racismo; victimización secundaria; conservantismo. 


\section{INTRODUÇÃO}

O racismo nacional não é um fenômeno novo, foi denunciado ainda na década de 1950 (Bastide \& Fernandes, 1959). Aquele período foi marcado pelo esforço do Governo e de intelectuais para difundir a ideia de que vivíamos uma democracia racial. Nos últimos anos, no entanto, o racismo no Brasil está se renovando e recrudescendo, aproveitando-se da expansão do conservadorismo político e moral que aconteceu em várias esferas da vida social (Lima, 2019), a ponto de, juntamente com outras formas de inferiorização da diferença, ter se tornado uma das mais importantes pautas sociais no Brasil. A intolerância racial está aumentando no país, com incremento significativo de denúncia de crimes associados ao racismo, a exemplo da injúria racial (Arcoverde, 2017), dos casos de animalização dos negros em estádios de futebol (Observatório da Discriminação Racial no Futebol brasileiro, 2019) ou, ainda, de discriminação racial de forma mais geral (Mauro, 2018).

Não obstante os impactos psicológicos (Yang, 2014), sociais, políticos e econômicos do racismo (Cohen, Fowler, Medenica, \& Rogowski, 2017), há ainda pouca literatura científica específica disponível sobre o tema no Brasil. Numa consulta feita nos periódicos da CAPES no dia 03 de abril de 2019, usando a palavra-chave "racismo", encontramos 453 registros do tema em títulos de publicações nacionais revisadas por pares. Reproduzindo a mesma pesquisa para publicações em língua inglesa aparecem 5.954 documentos. Quando analisamos as Dissertações e Teses defendidas sobre o tema, na mesma data no BDTD da CAPES, encontramos, dentre os 505495 documentos, 153 em cujo título aparece o termo "racismo", equivalendo a 0,03\% da produção nacional. Embora na psicologia brasileira o tema tenha começado a ser analisado desde o seu surgimento enquanto disciplina nas universidades por pensadores como Raul Briquet, Arthur Ramos, Donald Pierson, Virginia Leone Bicudo, Aniela Ginsberg e Dante Moreira Leite (ver Santos, Schucman, \& Martins, 2012 para uma revisão), há ainda pouca pesquisa e poucas publicações científicas divulgadas em periódicos nacionais. Até 2014 havia menos de 80 artigos publicados (Sacco, Couto, \& Koller, 2016). A título de comparação, a psicologia social norteamericana tem $10 \%$ dos artigos dos seus quatro principais periódicos tratando do racismo ou do preconceito (Dovidio, Hewstone, Glick, \& Esses, 2010).

Um dos fatores associados à baixa produção científica sobre racismo na psicologia do Brasil é a falta de instrumentos de pesquisa que permitam formular diagnósticos sobre o fenômeno e que sejam pouco obstruídos pelas normas que interferem nas respostas. Até onde vai nosso conhecimento, temos apenas dois instrumentos validados para estudo do racismo no Brasil: a escala de racismo cordial elaborada por Turra e Venturi (1995) e a escala norte-americana de racismo moderno, validada para o contexto brasileiro por Santos, Gouveia, Navas, Pimentel e Gusmão (2006). Face à escassez de produção a respeito da temática na ciência brasileira, bem como a carência de medidas do comportamento racista, este trabalho tem como objetivo a construção e validação de um 
instrumento de pesquisa do racismo ancorado no atual contexto de relações racializadas do Brasil.

\section{RACISMO: BREVE HISTÓRICO}

Os termos "raça" e "racismo" não surgiram ao mesmo tempo. O conceito moderno de raça foi inventado no século XVIII, sendo primeiramente associado à linhagem de aristocratas, pois se acreditava que passavam seu "sangue real" através das gerações (Fredrickson, 2015). Desde essa classificação já era possível observar que o termo se referia à noção de hierarquia. O termo "racismo", contudo, somente surge no início do século XX. Todavia, o racismo, enquanto fenômeno, já existia no início da Idade Moderna, associado às justificativas para o processo de colonização e escravidão e genocídio dos negros e indígenas (Miles, 1989).

No século XIX as políticas de naturalização da "diferença" emergem e se tornam um projeto de pretensão universal: "Naturalizar as diferenças significou, nesse momento, o estabelecimento de correlações rígidas entre características físicas e atributos morais." (Schwarcz, 1993, p.65). Para esta autora, a década de 1870 é considerada um marco para a história do Brasil, pois representou o momento em que as teorias racistas da Europa passaram a exercer um papel crucial no ideário positivo-evolucionista nacional.

Desde o seu surgimento o racismo possui "adequabilidade prática", pois se caracteriza como uma falsa explicação e representação de um processo social. As modernas sociedades, calcadas no individualismo e na busca pela realização, por apostarem na tese de que o esforço pessoal pode vencer qualquer dificuldade, tendem a explicar e mesmo justificar o "fracasso" e a exclusão social de amplos setores sociais por meio do racismo, considerando estes como decorrências das diferenças naturais entre os grupos humanos (Lima, 2014).

Nos EUA, o racismo começa a ser analisado, ainda na década de 1920, como uma resposta natural a "pessoas inferiores"; na década de 1930, ele é entendido como algo irracional e sem justificação; na década de 1940, são enfatizados seus aspectos inconscientes; nos anos 50, passa a ser concebido como problema da personalidade das mentes racistas; nas décadas de 1960 a 1970, a análise focava aspectos estratégicos, de norma social, voltados para os interesses grupais; finalmente na década de 1980 até os anos 2000, começam a ser investigados os correlatos universais e os processos automáticos de produção do racismo (Duckitt, 1992).

O racismo nacional também passou por diversas fases na sua análise, desde as teses da democracia racial de Gilberto Freyre, que caracteriza período de entre 1900 e 1940 como inteiramente livre de bloqueios institucionais para a igualdade entre as raças (Freyre, 1933/1983); desembocado na hipótese do "class-overrace", que afirmava que nosso preconceito era mais de classe social que de cor (Pierson, 1942); passando pelos trabalhos de Florestan Fernandes e da Escola de 
Sociologia paulista, que desmistificaram a tese da miscigenação como integração racial, propondo a existência de racismo no país e demonstrando como esse se associava à estratificação social (Fernandes, 1966). Até chegarmos, na década de 1990, quando se constata que em algumas esferas o Brasil da democracia racial era mais racista que o da África do Sul do Apartheid (Munanga, 1996).

Para autores como Santos et al. (2012) três períodos históricos podem ser destacados no pensamento psicológico brasileiro sobre relações étnico-raciais: 1 ) período entre o final do século XIX e o início do XX, dominado pelo modelo médico que considerava os negros como inferiores biologicamente; 2) período entre 1930 e 1950, marcado pela introdução da Psicologia no ensino superior, caracterizou-se pela crítica às noções biológicas de inferioridade racial e 3) período posterior a 1990, caracterizado pelos estudos sobre branqueamento e branquitude e pelos debates sobre Políticas de Ação Afirmativa.

A década de 1990 é fundamental para o entendimento das fases do racismo nacional. Nela, o governo federal reconhece oficialmente pela primeira vez a existência de racismo e começam a surgir as Políticas de Ação Afirmativa no país (Feres Jr. \& Campos, 2016), fato que marca a mudança de um racismo do "ninguém sabe ninguém viu", mais paternalista nas suas expressões, para um racismo mais hostil, ressentido pela perda de privilégios (Lima, Neves, \& Silva, 2014). Apesar das mudanças nas análises e expressões do racismo nacional, permanece como marca, desde a época de Gilberto Freyre, o mito da convivência harmoniosa das raças, típico de um racismo que nega publicamente sua existência, para se expressar mais livremente na esfera privada (Vieira, 2015). Parte da literatura psicossocial defende que o racismo age como um vírus que se transforma para sobreviver aos novos contextos (Dovidio \& Gaertner, 1998; Vala \& Pereira, 2012).

Podemos dizer que essa transfiguração do racismo se intensifica nos anos 2000, sobretudo a partir de 2013, com o avanço de narrativas conservadoras da extrema direita no Brasil (Lima, 2019). Desde então, vive-se no Brasil um momento em que muitas manifestações acerca dos negros e outras minorias sociais reputam a eles o problema, a causa do preconceito. Trata-se de um fenômeno semelhante à vitimização secundária ou revitimização; mas que guarda características próprias porque ao invés de alterar o locus de causalidade do fenômeno, afirma que ele não existe e que é apenas um artefato narrativo da minoria para, por um lado, manter ou alcançar posições sociais e econômicas, ou, por outro, justificar porque não alcança tais posições. Trata-se de um tipo de racismo que chamaremos neste artigo de revitimizador, pois se baseia na crença no "vitimismo" das minorias. Fenômeno muito associado à crítica ao "politicamente correto" que dominou a política norte-americana na última eleição presidencial (Michael, 2017).

Não obstante a importância de se estudar de forma sistemática o racismo num país que tem, excetuando alguns países africanos, a maior população negra do 
mundo, até a presente data apenas duas escalas de racismo foram ambientadas ao contexto nacional: a escala de racismo cordial e a escala de racismo moderno.

\section{RACISMO NO BRASIL: INSTRUMENTOS DE PESQUISA}

A escala de racismo cordial parte da ideia de que o racismo nacional se expressa em piadas e ditos populares marcados pelo verniz da "cordialidade". Ela é composta por 12 itens, nos quais as pessoas respondem entre "concordo totalmente" e "discordo totalmente", havendo, ainda, a opção "não sei". Alguns itens são: "Negro bom é negro de alma branca.", "Uma coisa boa do povo brasileiro é a mistura de raças.", "As únicas coisas que os negros sabem fazer bem são música e esportes.", etc. Essa escala foi aplicada a 5081 pessoas maiores de 16 anos em 121 municípios de todo o Brasil, no ano de 1995, quando se observou que $46 \%$ dos brancos afirmaram que "negro bom é negro de alma branca", 40\% destes acreditavam que "as únicas coisas que os negros sabem fazer bem são música e esportes" e $22 \%$ acreditavam que "as raças não deveriam se misturar" (Turra \& Venturi, 1995).

A escala de racismo moderno foi desenvolvida por McConahay e Hough (1976), no contexto das relações entre brancos e negros nos Estados Unidos. O pressuposto geral é o de que existe uma percepção de os negros estão recebendo mais direitos ou benefícios do que merecem e violando valores importantes para os brancos. Em decorrência disso, os itens da escala se baseiam em afirmações do tipo: "a discriminação é uma coisa do passado porque os negros podem agora competir e adquirirem as coisas que eles almejam"; "os negros estão subindo economicamente muito rápido e em setores nos quais não são bem-vindos"; "os meios e as demandas dos negros são inadequados ou injustos", etc. Tal escala foi validada para o contexto brasileiro por Santos et al. (2006). Os autores, partindo de uma versão que havia sido validada para o contexto espanhol, aplicam o instrumento a uma amostra de 269 pessoas, verificando a existência de duas dimensões do racismo moderno: "negação do preconceito", dimensão que ressalta a ideia de que o preconceito não existe, que é apenas um artefato para beneficiar os negros; e "afirmação de diferenças", que traduz a crença de que os negros possuem traços, sejam físicos, culturais ou estéticos, que os diferenciam dos brancos. Considerando que a escala variava de 1 a 7, os autores observam baixa adesão dos participantes à dimensão de negação do preconceito $(M=2,78, D P=0,94)$ e uma maior adesão aos itens da afirmação de diferenças $(M=3,93, D P=1,21)$.

Pires (2010) procede a uma comparação das escalas de racismo cordial e racismo moderno no Brasil, cotejando os escores das escalas com os de uma medida de Orientação para a Dominância Social (ODS) proposta por Sidanius (1993). A autora encontra resultados que indicam que a escala de racismo moderno, tratada de forma unidimensional, é mais sutil ou indireta que a de racismo cordial. Entretanto, os escores de ODS foram mais baixos que os escores médios 
de racismo moderno, indicando que mesmo assim a escala é muito reativa à norma antirracista.

Em que pese a importância dos dois instrumentos citados para o estudo do racismo, eles apresentam limitações. A escala de racismo cordial, ainda que tenha sido elaborada considerando aspectos culturais específicos do racismo nacional, foi aplicada num contexto político anterior às Políticas de Ação Afirmativa (PAA) e, portanto, não reflete elementos fundamentais do atual debate sobre racismo no Brasil. Além disso, se mostrou muito influenciada pela norma antirracista (Pires, 2010). Já a escala de racismo moderno, ainda que reflita o racismo pós PAA, foi ambientada num contexto específico das relações raciais dos EUA, e recebe um conjunto de críticas por confundir, na sua dimensão de negação do preconceito, racismo com conservadorismo político (Feldman \& Huddy, 2005).

O presente artigo traz dois estudos cujo objetivo geral foi a construção e a validação de uma escala de racismo mais contextualizada à atual conjuntura brasileira. Trata-se da Escala de Racismo Revitimizador (ERR). A ERR foi desenvolvida a partir da análise de conteúdo de comentários (posts online) em páginas na internet, cuja pauta foi o racismo. O Estudo 1 apresenta a construção da ERR. O Estudo 2 traz a validação convergente e discriminativa da escala.

\section{ESTUDO 1}

O objetivo do presente estudo foi construir e testar uma escala de racismo para o contexto brasileiro. Os itens que compõem o instrumento foram extraídos de comentários reais em páginas na internet. Eles foram, em seguida, submetidos a análises fatoriais exploratória e confirmatória.

\section{MÉTODO}

\section{ELABORAÇÃO DE ITENS}

A escala foi construída a partir de comentários em notícias da internet que tratavam de violências relacionadas ao racismo. A coleta dos materiais foi realizada no dia 29/01/2018 em sites de notícias sobre dois episódios de racismo ocorridos com estudantes universitários (ver G1, 07/01/18; Sou de Sergipe, 23/11/17) e uma matéria sobre a primeira diplomata negra do Itamaraty (Jornalistas Livres, 26/01/18). Esse material foi utilizado com o propósito de captar, nos discursos veiculados nos posts manifestações sutis e flagrantes de racismo. Foram então formuladas 28 afirmações racistas a partir dos comentários, as quais foram submetidas ao julgamento de dez juízes, todos pesquisadores do racismo. Esses juízes, estudantes de pós-graduação e integrantes de grupo de pesquisa sobre racismo, foram abordados numa sala de aula durante um seminário específico sobre o tema do racismo. Eles indicaram se o item expressava racismo e se era mais direto ou mais indireto. Foram mantidos 22 
itens, aqueles julgados como racistas em 100\% das avaliações; 20 considerados mais indiretos e dois com expressão mais flagrante de racismo.

\section{TESTAGEM DOS ITENS}

Foi realizado um estudo junto a uma amostra de 121 participantes, 50,4\% do sexo feminino, com idades variando de 18 a $62(\mathrm{M}=25,3, \mathrm{DP}=10,2)$. A maioria dos participantes foi composta por pessoas residentes em Sergipe (33,0\%), o restante residia em sete outros estados. Em relação à escolaridade, a maioria possuía nível superior, seja incompleto $(61,2 \%)$ ou completo (18,2\%). Os participantes se autodeclararam como pardos $(41,3 \%)$ brancos $(34,7 \%)$ e pretos $(12,4 \%)$. Outros $11,7 \%$ não se auto classificaram.

\section{PROCEDIMENTOS E INSTRUMENTOS}

Os dados foram obtidos por meio de questionário online divulgado em grupos e páginas em redes sociais. O questionário ficou disponível no período de 12/03/2018 até 23/04/2018. A escala foi composta por 22 itens (e.g., "As pessoas discutem o racismo mais do que deveriam", "No Brasil, com as políticas de ação afirmativa, os negros têm mais privilégios que os brancos.", "Independentemente da cor da pele, todos têm as mesmas oportunidades na vida desde que se esforcem."). A amplitude da escala variava de 1 (Discordo totalmente) a 5 (Concordo totalmente). Os participantes respondiam os itens em três situações: 1) auto posicionamento, informando como eles próprios se colocavam; 2) posição dos amigos, informando como avalia que seus amigos responderiam e 3) posição da sociedade, informando como avalia que os brasileiros, de forma geral, responderiam. Para realizar as análises foi utilizada a direção positiva da escala: quanto maior o valor, maior o racismo, e as respostas de auto posicionamento.

\section{ANÁLISE DE DADOS}

Os dados foram analisados com o Statistical Package for the Social Sciences (SPSS) e AMOS. Procedemos a análises fatoriais exploratórias e confirmatória para a configuração da escala. Em seguida realizamos estatísticas inferenciais com testes t de Student, Análises de Variância univariadas e testes de correlações de Pearson a fim de averiguarmos a adesão aos fatores encontrados e a relação desses com as variáveis sociodemográficas.

\section{ASPECTOS ÉTICOS}

No decorrer de toda a pesquisa, todas as exigências éticas e os princípios da pesquisa com seres humanos descritos na Resolução 510/2016 do CEP/CONEP foram respeitados. Todos os participantes contabilizados eram maiores de 18 anos e possuíam a liberdade de desistir a qualquer momento da sua participação na pesquisa sem qualquer perda, como descrito no Termo de Consentimento Livre e Esclarecido (TCLE). A pesquisa obteve aprovação no Comitê de Ética da Instituição sob Parecer n 2.898.213. 


\section{RESULTADOS E DISCUSSÃO}

Primeiramente, a escala de racismo passou por uma Análise Fatorial Exploratória (Principal Axis Factorig - PAF), com rotação oblíqua. Seguindo a literatura, predefinimos a análise para dois fatores intercorrelacionados, considerando que todas as teorias sobre os novos racismos propõem a existência de uma dimensão mais sutil e outra mais flagrante de expressão do fenômeno (ver Lima, 2014). A análise indicou que os itens são adequados para a fatorialização: teste de KMO = 0,895 e teste de esfericidade de Bartlett $=x^{2}(231)=1524,22 ; p<0,001$. Os dois fatores somados explicaram $46 \%$ da variância (ver Tabela 1 ).

O primeiro fator, composto por 16 itens, foi nomeado de Revitimização por apresentar conteúdo que reflete a crença de que os negros se fazem de vítima, e que a culpa do racismo é deles próprios. A crença na meritocracia também está presente nessa dimensão, destacando a percepção de que falta mais esforço por parte dos negros e que eles recebem mais da estrutura social do que merecem. Trata-se de uma dimensão que integra elementos das teses sobre os "novos racismos", pós Políticas de Ação Afirmativa (McConahay \& Hough, 1976), com elementos da retórica de que "se queixam demais, fazem mimimi", traduzindo uma crença de que se pararmos de falar do racismo ele desaparece. A média de adesão a esse fator foi de $2,49(D P=1,06)$, situando-se abaixo do ponto médio da escala (3), $t(120)=-5,32, p<0,001$. Esse Fator explicou $38 \%$ da variância e apresentou boa confiabilidade interna $(\alpha=0,93)$.

O segundo fator foi composto por seis itens que se relacionam à crença de que existem diferenças físicas e culturais entre brancos e negros e que uns grupos são biologicamente superiores aos outros. Trata-se de uma dimensão mais aberta, old fashioned, de racismo, presente também em algumas das modernas teorias sobre o fenômeno (e.g., Turra \& Venturi, 1995). Esse fator apresentou média de adesão mais baixa que o primeiro $(M=2,01, D P=0,75)$, e também abaixo do ponto médio da escala, $t(120)=-14,47, p<0,001$. A variância explicada foi igualmente baixa (8\%) e a confiabilidade interna moderada: $\alpha=0,68$.

Uma análise de correlações bivariadas indicou que a dimensão da Revitimização se correlaciona positivamente com a das Diferenças Físicas e Culturais, $r(121)=$ $0,31, p=0,001$. Testamos em seguida se a cor da pele dos participantes interferia na adesão aos fatores do racismo. Uma Anova One-Way indicou que a cor não afetou significativamente a dimensão das Diferenças Físicas e Culturais, $F(2,106)$ $=1,98, p=0,15$. Todavia, a cor da pele dos participantes teve um efeito tendencialmente significativo sobre a dimensão da Revitimização, $f(2,106)=$ $2,65, p=0,07$, indicando que os brancos apresentaram escores mais elevados ( $M$ $=2,82, D P=1,25)$ que os pretos $(M=2,11, D P=0,99)$ (Student-Newman-Keuls SNK $p<0,05)$. Os pardos $(M=2,47, D P=0,95)$ não se diferenciaram de brancos e pretos $(S N K p>0,10)$. 
Tabela 1.

Análise Fatorial (PAF) dos itens da ERR (rotação oblíqua).

\begin{tabular}{|c|c|c|}
\hline Item & F1 & F2 \\
\hline 1. As pessoas discutem o racismo mais do que deveriam. & 0,881 & -- \\
\hline $\begin{array}{l}\text { 2. No Brasil, com as políticas de ação afirmativa, os negros } \\
\text { têm mais privilégios que os brancos. }\end{array}$ & 0,871 & $-0,154$ \\
\hline $\begin{array}{l}\text { 11. É necessário haver uma reparação histórica para com a } \\
\text { população negra, por conta da escravidão e suas } \\
\text { consequências. * }\end{array}$ & 0,835 & -- \\
\hline $\begin{array}{l}\text { 3. O que chamam de "privilégio dos brancos" é, na verdade, } \\
\text { construído a partir do esforço das pessoas, e não uma } \\
\text { vantagem já existente. }\end{array}$ & 0,807 & -- \\
\hline $\begin{array}{l}\text { 4. Independentemente da cor da pele, todos têm as } \\
\text { mesmas oportunidades na vida desde que se esforcem. * }\end{array}$ & 0,772 & -- \\
\hline $\begin{array}{l}\text { 5. O racismo não deveria ser usado como justificativa para } \\
\text { não atingir objetivos pessoais. }\end{array}$ & 0,752 & -- \\
\hline $\begin{array}{l}\text { 6. Em geral, no Brasil, os brancos têm mais direitos do que } \\
\text { os negros. * }\end{array}$ & 0,747 & $-0,195$ \\
\hline
\end{tabular}

12. Independentemente da classe, todos têm as mesmas

0,713 oportunidades na vida desde que se esforcem.

7. O racismo só existe na cabeça das pessoas que se dizem

0,702 vítimas dele.

8. Se os negros tivessem mais força de vontade,

0,702 conseguiriam ascender socialmente tanto quanto os brancos.

9. Dizer que no Brasil há desigualdade de oportunidades $\quad 0,664$ entre brancos e negros é exagero.

13. Ter preferência estética por brancos em relação aos 0,574 negros não tem a ver com racismo, é apenas uma questão de gosto.

10. O racismo só se sustenta quando encontra aceitação 0,550 0,235 dos que se dizem discriminados.

14. Devemos respeitar as pessoas de cores diferentes, mas ninguém é obrigado a gostar delas.

15. Ter preferência estética por negros em relação aos brancos não tem a ver com racismo, é apenas uma questão de gosto. 
Tabela 1. Continuação.

\begin{tabular}{|c|c|c|}
\hline Item & F1 & F2 \\
\hline $\begin{array}{l}\text { 16. Se as pessoas negras não falassem tanto sobre o } \\
\text { racismo, ele não teria tanta força. }\end{array}$ & 0,322 & 0,292 \\
\hline $\begin{array}{l}\text { 17. Os negros, por terem mais força física, são mais aptos a } \\
\text { trabalhos braçais }\end{array}$ & 0,166 & 0,602 \\
\hline 18. Os negros possuem maior talento para dança. & -- & 0,590 \\
\hline $\begin{array}{l}\text { 19. De forma geral, negros e brancos possuem tradições e } \\
\text { valores diferentes. }\end{array}$ & $-0,181$ & 0,543 \\
\hline 20. Os negros são mais dotados fisicamente. & 0,251 & 0,477 \\
\hline $\begin{array}{l}\text { 21. Há grupos humanos biologicamente superiores a } \\
\text { outros. }\end{array}$ & -- & 0,455 \\
\hline $\begin{array}{l}\text { 22. Há diferenças entre as características biológicas dos } \\
\text { negros e brancos. }\end{array}$ & 0,123 & 0,336 \\
\hline Autovalores (Eigenvalues) & 8,32 & 1,73 \\
\hline Variância explicada (\%) & 37,8 & 7,9 \\
\hline Consistência interna (Alfa de Cronbach) & 0,93 & 0,68 \\
\hline
\end{tabular}

Nota. *Itens invertidos para as análises.

A variância explicada, a desproporção do número de itens em cada fator, bem como os valores dos alfas de Cronbach, apontaram para uma possível direção unifatorial da escala. Além disso, os Eigenvalues sinalizam para a quase não fatoriabilidade do Fator 2. Para testar essa hipótese, procedemos a uma Análise Fatorial Confirmatória, utilizando o Amos 24.0 e adotando o método Maximum Likelihood. Foram testados dois modelos: um modelo multidimensional, tal como configurado na Tabela 1, e um modelo alternativo apenas com o $1^{\circ}$ fator da PAF. Os resultados obtidos foram interpretados com base em três índices de ajuste global: RMSEA, GFI e CFI (Billiet \& McClendon 2000; Shevlin \& Miles, 1998). Valores de RMSEA devem ser inferiores a 0,05 para indicar um bom ajuste de modelo. No caso do GFI e CFI, quando o escore é maior que 0,90 há indicações adicionais de um ajuste satisfatório do modelo (Hu \& Bentler, 1999).

$\mathrm{Na}$ primeira análise testamos a estrutura multidimensional da escala. Os indicadores de qualidade de ajuste do modelo foram muito baixos: GFI = 0,756; CFI $=0,826$ e RMSEA $=0,099$. Resultado que nos levou, numa segunda análise confirmatória, a testar a adequabilidade da escala como unifatorial (Fator 1), com 16 itens. Embora os indicadores de qualidade de ajuste desse segundo modelo sejam melhores que os do anterior, ele ainda não é estatisticamente sólido, uma vez que CFI, RMSEA e GFI estiveram abaixo ou acima do recomendado: GFI = 0,$799 ; \mathrm{CFI}=0,844$ e RMSEA $=0,126$. 
Finalmente, procedemos a modificações no arranjo dos itens no fator, a fim de aumentar o ajuste do modelo e alcançar uma configuração consistente. Essas mudanças incluíram a exclusão de seis itens cujas correlações com o modelo eram mais baixas e a introdução de correlações entre alguns termos de erro (e1e2, e1 - e3, e3 - e6, e4 - e5, e7 - e9). Testamos esse novo modelo utilizando o recurso bootstrap para simular os resultados em 1000 amostras. A adição dessas correlações resultou em um modelo que cumpre todos os pré-requisitos de ajuste: $X^{2}(35)=35,55, p=0,30 ; \mathrm{GFI}=0,943 ; \mathrm{CFI}=0,995$ e RMSEA $=0,031$. Como pode ser observado na Figura 1 , as cargas fatoriais foram significativas. Já as saturações foram positivas e diferentes de zero, com coeficiente padronizado médio de 0,76 e amplitude 0,52 a 1,00. Esses resultados indicam a confirmação da estrutura unifatorial e com dez itens da escala. Os dez itens mantidos na versão final receberam número de 1 a 10 na Tabela 1.

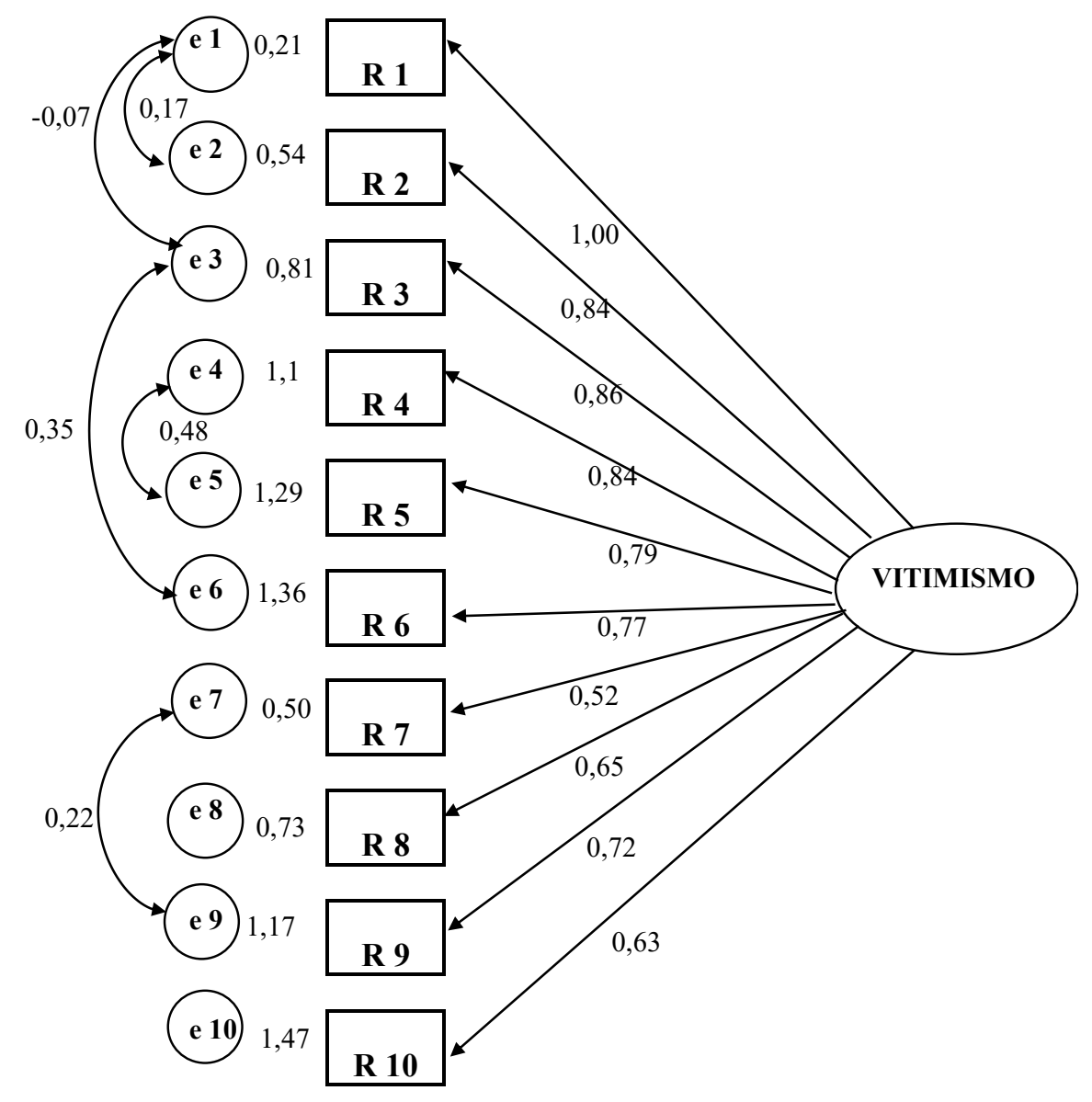

Figura 1.

Análise Fatorial Confirmatória da Escala de Racismo Revitimizador (10 itens). 
A versão final da ERR obteve um escore médio de 2,29 (DP = 1,13), abaixo do ponto médio da escala, $\mathrm{t}(129)=-6,84, \mathrm{p}<0,001$. A cor da pele dos participantes teve agora um efeito significativo sobre o racismo, $F(2,106)=2,95, p=0,05$, indicando que os brancos apresentaram escores mais elevados de Racismo Revitimizador $(M=2,67, D P=1,32)$ que os pretos $(M=1,88, D P=1,04)$ (Student-Newman-Keuls - SNK $p<0,05)$. Os pardos $(M=2,27$, $D P=1,03$ ) não se diferenciaram de brancos e pretos (SNK $p>0,10$ ). O fato de termos um efeito da cor da pele dos participantes na adesão ao racismo, mostrando maior escore dos brancos que dos pretos, indica que a medida é menos obstrutiva para mensuração do racismo, como propõem McConahay e Hough (1976), na construção da escala de racismo moderno. Além disso, considerando o racismo e o antirracismo como normas sociais (Lima, 2014), a análise dos escores de racismo atribuídos aos amigos $(\mathrm{M}=2,47$; $\mathrm{DP}=0,96)$ e, sobretudo, aos brasileiros $(M=3,28 ; D P=0,72)$, escore este acima do ponto médio da escala, $t(120)=3,96$, $p<0,001$, demonstram que a ERR se mostra confiável, tanto para a pesquisa do racismo individual quanto para a análise da percepção de racismo na sociedade. A confiabilidade interna de ambas escalas alternativas foi elevada: ERR-Amigos, $\alpha$ $=0,91$ e ERR-Brasil, $\alpha=0,86$.

Tendo encontrado a estrutura e o conteúdo da Escala de Racismo Revitimizador (ERR), torna-se necessário proceder à sua validação convergente e discriminativa. Para tanto, realizamos um segundo estudo.

\section{ESTUDO 2}

O presente estudo procedeu à validação da Escala de Racismo Revitimizador (ERR) mediante análises convergente e discriminativa. Para a análise de validação convergente foi utilizada a escala de racismo moderno adaptada para o Brasil por Santos et al. (2006) e para a validação discriminativa a escala de autoritarismo de extrema-direita de Altmeyer (1981). Para testarmos o caráter de obstrutividade da ERR utilizamos as escalas de motivação externa e interna para responder sem preconceito de Plant e Devine (1998), adaptadas para o Brasil por Gouveia, Souza Filho, Araújo, Guerra e Sousa (2006). Também controlamos nas análises os efeitos da posição política no espectro Esquerda-Direita, a fim de evitar confundir racismo com conservadorismo político de direita (Feldman \& Huddy, 2005).

\section{MÉTODO}

A amostra foi composta por 104 participantes, sendo a maioria do sexo masculino (54,8\%), com idades variando de 18 a 71 anos $(M=22,9, D P=7,3)$. A maioria informou morar em Sergipe $(79,8 \%)$, apesar de haver pessoas de 12 outros estados. A escolaridade predominante foi de nível superior, seja incompleto $(69,2 \%)$ ou completo (18,3\%). Em relação à cor da pele, $23,1 \%$ se auto classificaram como pretos, $44,2 \%$ como pardos e $25 \%$ como brancos. A renda familiar variou de até um salário mínimo (30\%) até mais de 8 (4\%). Em relação à 
posição política no espectro Esquerda-Direita, 44\% se colocaram à esquerda, 31\% no centro, $6 \%$ à direita e os restantes $19 \%$ não se posicionaram.

\section{PROCEDIMENTOS E INSTRUMENTOS}

Os dados foram obtidos por meio de questionário online divulgado em grupos e páginas em redes sociais, assim como no Estudo 1 . O questionário ficou disponível no período de 11/09/2018 até 26/11/2018. Foram utilizados, além de um bloco de questões sociodemográficas, quatro outros. O primeiro, foi a Escala de Racismo Revitimizador (ERR) do Estudo 1, composta de 10 itens. A amplitude da escala variou de 1 (Discordo totalmente) a 5 (Concordo totalmente). A média de adesão neste estudo foi de 1,67 ( $D P=0,68)$, inferior ao ponto médio (3), $t(103)=-19,80, p<0,001$. A consistência interna foi novamente elevada ( $\alpha=$ $0,91)$.

O segundo bloco foi a escala de Racismo Moderno, adaptada para o contexto brasileiro por Santos et al. (2006), composta por 14 itens divididos em duas dimensões: "Negação do Preconceito", composta por 9 itens, e "Afirmação das Diferenças", composta por 5 itens. A amplitude de respostas variou de 1 (Discordo totalmente) a 5 (Concordo totalmente). A dimensão da afirmação de diferenças apresentou média de adesão de $2,9(D P=0,48)$, valor que não difere do ponto médio da escala, $t(102)=-1,5$, n.s. A consistência interna dessa dimensão foi elevada $(\alpha=0,80)$. A dimensão de negação do preconceito apresentou adesão mais baixa $(M=1,6 ; D P=0,54)$, abaixo do ponto médio, $t(102)=-26,2 ; p<0,001$. A consistência interna deste fator também foi satisfatória $(\alpha=0,87)$. A escala de racismo moderno sem divisão em fatores apresentou baixo escore de racismo $(M=2,1 ; D P=0,41), t(102)=-21,3 ; p<$ 0,001 . A consistência interna manteve-se elevada $(\alpha=0,86)$.

A terceira escala utilizada foi a de Autoritarismo, composta por 22 itens. Tal escala foi uma adaptação ao contexto brasileiro da escala RWA (Right Wing Authoritarianism) de Altemeyer (1981) feita por Vilela (2012). A amplitude variou de 1 (Discordo totalmente) a 9 (Concordo totalmente). O escore de adesão dos participantes foi baixo $(M=2,43 ; D P=1,24)$. Um teste t contra o ponto médio (5), indicou que este valor está abaixo, $t(102)=-20,98 ; p<0,001)$. A consistência interna foi satisfatória $(\alpha=0,93)$.

A quarta e última escala foi a de motivação interna e externa para responder sem preconceito (Plant \& Devine, 1998), adaptada ao contexto brasileiro por Gouveia et al. (2006). Tal escala sugere que ao expressar seus níveis de preconceito, alguns indivíduos são mais fortemente afetados pela norma antirracista do que outros, de forma que uns teriam interiorizado a norma e se tornado igualitários, ao passo que outros apenas a aceitaram e se tornaram sutis ou velados nas suas expressões (Plant \& Devine, 2001). Essa escala foi composta por 9 itens e duas subescalas: Motivação Externa e Motivação Interna, com 5 e 4 itens respectivamente. Suas possibilidades de respostas variaram de 1 (Discordo totalmente) a 5 (Concordo totalmente). O escore de motivação externa foi baixo 
$(M=1,9 ; D P=0,76), t(103)=-13,40 ; p<0,001)$, a consistência interna aceitável $(\alpha=0,81)$. A subescala de motivação interna apresentou alta adesão $(M=3,9 ; D P$ $=0,46), t(103)=20,10 ; p<0,001$ e moderada consistência interna $(\alpha=0,69)$.

\section{ANÁLISE DE DADOS E ASPECTOS ÉTICOS}

Os dados foram analisados com o SPSS. Procedemos a um teste de correlações parciais de Pearson, controlando o efeito das variáveis sociodemográficas sexo, cor da pele, idade e renda familiar. Esse procedimento foi adotado porque alguns estudos têm encontrado interferências dessas variáveis nos escores de racismo (e.g., Cohen et al., 2017; Turra \& Venturi, 1995); controlamos ainda o efeito da posição política no espectro Esquerda-Direita, uma vez que a literatura tem mostrado que essa variável interfere nos índices de conservadorismo, o qual se associa com o racismo (e.g., Feldman \& Huddy, 2005; Lima, Almeida, Araujo, \& Barbosa, 2019). O presente estudo foi inserido no mesmo projeto do estudo 1 , já aprovado pelo CET.

\section{RESULTADOS E DISCUSSÃO}

Para análise de validação da ERR procedemos a correlações parciais controlando os efeitos do sexo, cor da pele, idade, renda e posição política dos participantes. No que tange à validação convergente, a ERR apresentou correlações positivas com as duas dimensões de racismo moderno e com a escala como um todo. A dimensão de negação do preconceito apresentou uma correlação mais forte. Tal resultado indica uma validação convergente da ERR, visto que o conteúdo da nossa escala consiste mais em negar a existência do preconceito do que em afirmar as diferenças entre os grupos (ver Tabela 2).

No que diz respeito à validação discriminativa, os resultados apontam uma correlação positiva entre a ERR e a escala de autoritarismo (RWA). Esse resultado era esperado, uma vez que sabemos que o autoritarismo é uma das bases do racismo (Bret, Beffara, McFadyen, \& Mermillod, 2017). Entretanto, quando colocamos, numa Regressão Linear, o autoritarismo para explicar o Racismo Revitimizador, observamos que apenas 7\% deste é explicado pela adesão à RWA, $\left[R^{2}=0,69, f(1,95)=8,03, p=0,006\right]$. Tal resultado indica que a ERR apresenta validade divergente ou discriminativa em relação à RWA.

Finalmente, as correlações entre a ERR e as dimensões da motivação para responder sem preconceito não foram significativas, indicando que a nossa medida de racismo é pouco reativa ao politicamente correto ou à norma antirracista. Inclusive mostrando-se como menos reativa que a escala de Racismo Moderno, a qual apresentou correlação positiva com a motivação externa. $\mathrm{Na}$ mesma direção, outros estudos verificam que indivíduos mais motivados externamente a responderem sem preconceito geralmente são os mais afetados pela pressão de serem politicamente corretos, se mostrando mais preconceituosos quando não pressionados a cumprir essas normas (Plant \& Devine, 2001). 
Tabela 2.

Matriz de Correlações Parciais de Pearson $(n=121)$ (controladas por sexo, cor da pele, idade, renda e posição política no espectro Esquerda-Direita)

\begin{tabular}{l|c|c|c|c|c|c}
\multicolumn{1}{c|}{ Fator } & 1 & 2 & 3 & 4 & 5 & 6 \\
$\begin{array}{l}\text { 1. Escala de Racismo } \\
\text { Revitimizador }\end{array}$ & 1 & -- & -- & -- & -- & -- \\
2. Negação do preconceito & $0,79^{* \star *}$ & 1 & -- & -- & -- & -- \\
3. Afirmação de diferenças & $0,21+$ & 0,17 & 1 & -- & -- & -- \\
4. Racismo moderno total & $0,70^{* * *}$ & $0,83^{* * *}$ & $0,69 * *$ & 1 & -- & -- \\
5. Autoritarismo & $0,25^{*}$ & $-0,01$ & 0,17 & 0,09 & 1 & -- \\
6. Motivação externa & 0,19 & $0,30^{* *}$ & 0,02 & $0,23^{*}$ & 0,17 & 1 \\
7. Motivação interna & $-0,13$ & $-0,16$ & 0,02 & $-0,10$ & 0,08 & 0,03 \\
\hline
\end{tabular}

Nota. ${ }^{+} \mathrm{p}<0,10 ;{ }^{*} \mathrm{p}<0,05 ;{ }^{* *} \mathrm{p}<0,01 ;{ }^{* \star *} \mathrm{p}<0,001$.

\section{CONSIDERAÇÕES FINAIS}

Este trabalho apresentou como objetivo a construção e validação de um instrumento de pesquisa contextualizado no atual cenário de expressões do racismo no Brasil. A hipótese de análise adotada era a de que, face à nova conjuntura política e social mais conservadora, o racismo se manifesta pela atribuição de excesso retórico, "mimimi", e de culpa às minorias. Em função disso, decidimos chamar esse "novo" racismo de revitimizador. A escala construída para pesquisá-lo partiu de comentários postados na internet. Procedemos, então à construção e validação do instrumento. No primeiro estudo, foram verificadas duas dimensões do racismo, a da revitimização foi a mais bem estruturada e consistente, por isso retida para as análises subsequentes. No segundo estudo, validamos $o$ instrumento de forma convergente, com a escala de racismo moderno, e discriminativa com o autoritarismo de extrema direita. Também procedemos a uma análise confirmatória da estrutura da escala.

Os resultados indicaram a Escala de Racismo Revitimizador (ERR) apresenta validade e que é menos influenciada pela motivação para responder sem preconceito que a escala de racismo moderno; mostrando-se, portanto, como instrumento útil para pesquisar o tema, sobretudo, por estar mais atualizado ao contexto nacional de expressão do racismo que os dois principais instrumentos que dispomos no momento (escala de racismo moderno e escala de racismo cordial).

Todavia, uma limitação importante da ERR precisa ser destacada. Não obstante esta ter se mostrado válida interna e externamente, e ter sido menos sensível à norma antirracista que a escala de racismo moderno, ela ainda produz reatividade nos participantes, uma vez que as médias de adesão nos dois estudos 
foram baixas. Pensamos que esse efeito se deve ao tipo de coleta e consequente amostra que obtivemos nos dois estudos. Coletas de dados via questionários eletrônicos geralmente produzem certa uniformização do perfil da amostra (Wachelke, Natividade, Andrade, Wolter, \& Camargo, 2014), no caso do nosso estudo são sobretudo estudantes universitários, geralmente menos aderentes ao conservadorismo e mais atentos às normas antipreconceito (Cohen et al., 2017; Lima et al., 2019). Cabe destacar que controlamos o efeito da posição política nas análises feitas no segundo estudo e mesmo assim a ERR se manteve consistente.

Outra limitação que pode ser apontada é a de não termos feito um estudo semântico específico para análise da compreensão dos itens por parte dos participantes. Todavia, como o conteúdo da escala foi extraído de comentários na internet em páginas visitadas por muitos usuários, como os juízes do estudo piloto não apontaram problemas com os enunciados, como na coleta de dados não foram apontadas pelos participantes dificuldades de resposta e como obtivemos elevada consistência interna entre os itens, pensamos que esse aspecto não afetou a qualidade da escala. Novas investigações, com amostras mais diversificadas, poderão atestar ainda mais as propriedades heurísticas e psicométricas do instrumento proposto.

Não obstante esses limites, consideramos importante ter uma escala parcimoniosa e mais coerente com atual realidade de relações racializadas do Brasil para estimular as pesquisas sobre um tema que está se tornando um dos mais importantes problemas em todo o mundo, culminando em genocídios e negação de direitos às minorias étnicas e que, na psicologia do Brasil, tem recebido ainda pouca atenção.

\section{REFERÊNCIAS}

Altemeyer, B. (1981). Right wing authoritarianism. Winnipeg: University of Manitoba Press.

Arcoverde, L. (2018, 27 de julho). Crimes de racismo e injúria racial crescem 29\% em São Paulo em 2018. Globo News, Recuperado de https://g1.globo.com/sp/saopaulo/noticia/2018/07/27/crimes-de-racismo-e-injuria-racial-crescem-29-em-sao-pauloem-2018.ghtml

Bastide, R., \& Fernandes, F. (1959). Brancos e negros em São Paulo. São Paulo, SP: Companhia Editora Nacional.

Billiet, J. B., \& McClendon, M. J. (2000). Modeling acquiescence in measurement models for two balanced sets of items. Structural Equation Modeling, 74), 608-628. doi:10.1207/S15328007SEM0704_5

Bret, A., Beffara, B, McFadyen, J., \& Mermillod, M. (2017). Right wing authoritarianism is associated with race bias in face detection. PloSOne, 12(7), e0179894. doi:10.1371/journal.pone.0179894.

Cohen, C. J., Fowler, M., Medenica, V. E., \& Rogowski, J. C. (2017). The 'Woke' Generation? Millennial Attitudes on Race in the US. Recuperado de https://genforwardsurvey.com/assets/uploads/2017/10/GenForward-Oct-2017-FinalReport.pdf

Dovidio, J. F. \& Gaertner, S. L. (1998). On the nature of contemporary prejudice: The causes, consequences, and 'challenges of aversive racism. In J. L. Eberhardt \& S. T. Fiske (Eds.), Confronting Racism: The problem and the response (pp. 3-32). Califórnia: SAGE. 
Dovidio, J. F., Hewstone, M., Glick, P., \& Esses, V. M. (2010). Prejudice, stereotyping and discrimination: Theoretical and empirical overview. Em J. F. Dovidio, M. Hewstone, P. Glick, \& V. M. Esses (Eds.), The SAGE handbook of prejudice, stereotyping and discrimination, (pp. 3-29). Califórnia: SAGE.

Duckitt, J. (1992). Psychology and prejudice: A historical analysis and integrative Framework. American Psychologist, 47(10),1182-1193. doi: 10.1037/0003-066X.47.10.1182

Feldman, S., \& Huddy. L. (2005). Racial Resentment and white opposition to race-conscious programs: Principles or prejudice?. American Journal of Political Science, 49(1), 168-183. doi: $10.2307 / 3647720$

Feres Jr., J., \& Campos, L. A. (2016). Ação afirmativa no Brasil: Multiculturalismo ou justiça social? Lua Nova, 99, 257-293. doi:10.1590/0102-6445257-293/99

Fernandes, F. (1966). O Negro no mundo dos brancos. São Paulo, SP: Difusão Européia do Livro.

Fredrickson, G. M. (2015). Racism: A short history. Nova Jersey: Princeton University Press.

Freyre, G. (1933/1983). Casa-grande e senzala: Formação da família brasileira sob o regime de economia patriarcal. Lisboa: Edição Livros do Brasil.

G1 (2018, 07 e janeiro). Blog com mensagens racistas sobre estudantes provoca revolta em universidade do Rio. Recuperado de https://g1.globo.com/rj/rio-de-janeiro/noticia/blogcom-mensagens-racistas-sobre-estudantes-negros-provoca-revolta-em-universidade-dorio.ghtml

Gouveia, V. V., Souza Filho, M. L., Araújo, A. G. T., Guerra, V. M., \& de Sousa, D. F. M. (2006). Correlatos valorativos das motivações para responder sem preconceito. Psicologia: Reflexão e Crítica, 19(3), 422-432. doi:10.1590/S0102-79722006000300011

Hu, L. T., \& Bentler, P. M. (1999). Cutoff criteria for fit indexes in covariance structure analysis: Conventional criteria versus new alternatives. Structural Equation Modeling: $A$ Multidisciplinary Journal, 6, 1-55. doi:10.1080/10705519909540118

Jornalistas Livres (2018, 26 de janeiro). Piauiense é a primeira negra diplomata no Itamaraty. Recuperado

de www.facebook.com/jornalistaslivres/photos/a.292153227575228/680009545456259/?type =38theater

Lima, M. E. O (2014). Preconceito. In A. R. R. Torres, L. Camino, M. E. O. Lima, \& M. E. Pereira (Eds.). Psicologia social: Temas e teorias (pp. 589-642). Brasília, DF: Techonopolitik.

Lima, M. E. O. (2019). O que há de "novo" no novo racismo do Brasil? Revista Ensaios e Pesquisas em Educação e Cultura, 4, 155-177. doi:10.29327/211303

Lima, M. E. O., Almeida, J. N., Araujo, E. M. S., \& Barbosa, I. H. A. (2019). Crise, anomia e identificação com o Brasil de 2014 a 2018. In A. Faro, M. E. O. Lima, D. França, S. Enumo, \& C. Pereira. (Eds.). Psicologia Social e Psicologia da Saúde. Tópicos atuais (p. 33-52). Curitiba, PR: CRV.

Lima, M. E. O., Neves, P. S. da C., \& Silva, P. B. (2014). A implantação das cotas na Universidade: Paternalismo e ameaça à posição dos grupos. Revista Brasileira de Educação, 19(56), 141164. doi:10.1590/S1413-24782014000100008

Mauro, M. (2018, 20 de novembro). Denúncias de discriminação racial aumentam 43,75\% de 2017 para 2018. Destak, Recuperado de https://www.destakjornal.com.br/cidades/rio-dejaneiro/detalhe/denuncias-de-discriminacao-racial-aumentam-4375-de-2017-para-2018

McConahay, J. B., \& Hough, J. C. Jr. (1976). Symbolic racism. Journal of Social Issues, 32(2), 23-45. doi:10.1111/j.1540-4560.1976.tb02493.x

Michael, G. (2017). The rise of the alt-right and the politics of polarization in America. Skeptic, 22, 917.

Miles, R. (1989). Racism. Londres: Routledge.

Munanga, K. (1996). As facetas de um racismo silenciado. In L. M. Schwarcz, R. D. S. \& Queiroz, (Eds). Raça e diversidade (pp. 213-229). São Paulo, SP: Estação Ciência, Universidade de São Paulo.

Observatório da Discriminação Racial no Futebol Brasileiro (2019). Futebol racista: A discriminação de ontem e hoje. Recuperado de https://observatorioracialfutebol.com.br/textos/futebolracista-a-discriminacao-de-ontem-e-hoje/

Pierson, D. (1942). Negroes in Brazil: A study of race contact at Bahia. Carbondale II: Southern Illinois University Press.

Pires, A. M. L. T. (2010). El prejuicio racial en Brasil: Medidas comparativas. Psicologia \& Sociedade, 22(1), 32-42. doi:10.1590/S0102-71822010000100005 
Plant, E. A., \& Devine, P. G. (1998). Internal and external motivation to respond without prejudice. Journal of Personality and Social Psychology, 75(3), 811-832. doi:10.1037/00223514.75.3.811

Plant, E. A., \& Devine, P. G. (2001). Responses to other-imposed pro-Black pressure: Acceptance or backlash?. Journal of Experimental Social Psychology, 37, 486-501. doi:10.1006/jesp.2001.1478.

Sacco, A. M., Couto, M. C. P. de P., \& Koller, S. H. (2016). Revisão sistemática de estudos da psicologia brasileira sobre preconceito racial. Temas em Psicologia, 24(1), 233-250. doi:10.9788/TP2016.1-16

Santos, A. O., Schucman, L. V., \& Martins, H. V. (2012). Breve histórico do pensamento psicológico brasileiro sobre relações étnico-raciais. Psicologia: Ciência e Profissão, 32, 166-175. doi:10.1590/S1414-98932012000500012.

Santos, W. S., Gouveia, V. V., Navas, M. S., Pimentel, C. E., \& Gusmão, E. E. (2006). Escala de racismo moderno: Adaptação ao contexto brasileiro. Psicologia em Estudo Maringá, 11(3), 637-645. doi:10.1590/S1413-73722006000300020.

Schwarcz, L. M. (1993). O espetáculo das raças: Cientistas, instituições e questão racial no Brasil do século XIX. São Paulo, SP: Editora Companhia das Letras.

Shevlin, M., \& Miles, J. N. (1998). Effects of sample size, model specification and factor loadings on the GFI in confirmatory factor analysis. Personality and Individual Differences, 25, 85-90. doi:10.1016/S0191-8869(98)00055-5

Sidanius, J. (1993). The psychology of group conflict and the dynamics of oppression: A social dominance perspective. In S. Iyengar, \& W. McGuire (Eds.), Explorations in political psychology (pp. 183-219). Durham, NC: Duke University Press.

Sou de Sergipe (2017, 23 de novembro). Sou de Sergipe, Recuperado de https://www.youtube.com/watch?v=0hVh2Z6fXRA

Vala, J., \& Pereira, C. (2012). Racism: An evolving virus. In: F. Bettencourt, A. J. Pearce (Eds.) Racism and ethnic relations in the portuguese-speaking world (pp. 49-70). New York, NY: Oxford University Press.

Turra, C., \& Venturi, G. (1995). Racismo cordial: A mais completa análise sobre o preconceito de cor no Brasil. São Paulo, SP: Editora Ática.

Vieira, R. M. (2015). Racismo à moda da casa. GV Executivo, 14, 62. doi:10.12660/gvexec.v14n1.2015.49196

Vilela, M. O. (2012). A Personalidade autoritária do chão de fábrica à gerência: Um estudo aplicando a Escala RWA adaptada da Escala " $F$ " de Adorno. (Dissertação de mestrado). Pontifícia Universidade Católica de Minas Gerais, Belo Horizonte, Brasil. Recuperado de http://www.biblioteca.pucminas.br/teses/Administracao_VilelaMO_1.pdf.

Wachelke, J., Natividade, J., Andrade, A., Wolter, R., \& Camargo, B. (2014). Caracterização e avaliação de um procedimento de coleta de dados online (CORP). Avaliação Psicológica, 13(1), 143146.

Yang, J. (2014). Effect of racism on African American women's development of psychological distress: The role of psychological wellbeing and racism-related social support. Theses and Dissertations, Iowa State University. Recuperado de https://lib.dr.iastate.edu/etd/13873.

\section{AGRADECIMENTOS}

Os autores agradecem ao Conselho Nacional de Desenvolvimento Científico e Tecnológico (CNPq) e à Universidade Federal de Sergipe (UFS) pelo financiamento e infraestrutura de pesquisa. Agradecem, ademais, ao professor André Faro pela leitura de versão inicial do texto.

\section{CONFLITOS DE INTERESSES}

Não há conflito de interesses.

\section{FINANCIAMENTO}

Financiamento pelo Conselho Nacional de Desenvolvimento Científico e Tecnológico (CNPq) e Universidade Federal de Sergipe (UFS). 


\section{SOBRE OS AUTORES}

Marcus Eugênio Oliveira Lima é psicólogo e mestre pela Universidade Federal da Paraíba (UFPb) e doutor em psicologia social pelo ISCTE-PT. Trabalha na linha psicologia cognitiva e social.

E-mail: marcuseolima@gmail.com

(1) http://orcid.org/0000-0001-5280-130X

Isabelle Haaiara Andrade Barbosa é graduanda em Psicologia pela Universidade Federal de Sergipe (UFS). Membro do grupo de pesquisa: Normas Sociais, Estereótipos, Preconceito e Racismo (NSEPR) da UFS.

E-mail: isabelle.hab@outlook.com

(1) https://orcid.org/0000-0003-1535-3047

Erick Matheus dos Santos Araujo é graduando em Psicologia pela Universidade Federal de Sergipe (UFS). Bolsista PIBIC-UFS e membro do grupo de pesquisa: Normas Sociais, Estereótipos, Preconceito e Racismo (NSEPR) da UFS.

E-mail: erick erickmatheus@hotmail.com

(1) https://orcid.org/0000-0002-5365-8354

Juliana Nascimento de Almeida é graduanda em Psicologia pela Universidade Federal de Sergipe (UFS). Bolsista PIBIC-CNPq e membro do grupo de pesquisa: Normas Sociais, Estereótipos, Preconceito e Racismo (NSEPR) da UFS.

E-mail: jujsalmeida@hotmail.com

(3) https://orcid.org/0000-0001-9381-1774 